\title{
The discovery of biological subphenotypes in ARDS: a novel approach to targeted medicine?
}

Karin Wildi ${ }^{1,2,3^{*}}$ D, Samantha Livingstone ${ }^{1,2}$, Chiara Palmieri ${ }^{4}$, Gianluigi LiBassi ${ }^{1,2}$, Jacky Suen ${ }^{1,2}$ and John Fraser ${ }^{1,2}$

\begin{abstract}
The acute respiratory distress syndrome (ARDS) is a severe lung disorder with a high morbidity and mortality which affects all age groups. Despite active research with intense, ongoing attempts in developing pharmacological agents to treat ARDS, its mortality rate remains unaltered high and treatment is still only supportive. Over the years, there have been many attempts to identify meaningful subgroups likely to react differently to treatment among the heterogenous ARDS population, most of them unsuccessful. Only recently, analysis of large ARDS cohorts from randomized controlled trials have identified the presence of distinct biological subphenotypes among ARDS patients: a hypoinflammatory (or uninflamed; named P1) and a hyperinflammatory (or reactive; named P2) subphenotype have been proposed and corroborated with existing retrospective data. The hyperinflammatory subphenotyope was clearly associated with shock state, metabolic acidosis, and worse clinical outcomes. Core features of the respective subphenotypes were identified consistently in all assessed cohorts, independently of the studied population, the geographical location, the study design, or the analysis method. Additionally and clinically even more relevant treatment efficacies, as assessed retrospectively, appeared to be highly dependent on the respective subphenotype. This discovery launches a promising new approach to targeted medicine in ARDS. Even though it is now widely accepted that each ARDS subphenotype has distinct functional, biological, and mechanistic differences, there are crucial gaps in our knowledge, hindering the translation to bedside application. First of all, the underlying driving biological factors are still largely unknown, and secondly, there is currently no option for fast and easy identification of ARDS subphenotypes. This narrative review aims to summarize the evidence in biological subphenotyping in ARDS and tries to point out the current issues that will need addressing before translation of biological subohenotypes into clinical practice will be possible.
\end{abstract}

Keywords: Acute respiratory distress syndrome (ARDS), Subphenotypes, Targeted treatment, Cluster analysis, Precision medicine, Predictive and prognostic enrichment, Biomarker

\section{Introduction}

Described first in 1967 [1], acute respiratory distress syndrome (ARDS) is an acute severe inflammation of both lungs caused by various etiologies, either by direct

\footnotetext{
* Correspondence: k.wildi@uq.edu.au

${ }^{1}$ The Critical Care Research Group, The Prince Charles Hospital, Clinical Sciences Building, Level 3, Chermside, Brisbane, QLD 4032, Australia ${ }^{2}$ Faculty of Medicine, The University of Queensland, Brisbane, Australia Full list of author information is available at the end of the article
}

pulmonary or by indirect systemic injury [2-4]. Multiple and heterogenous causes are known to result in ARDS, which is pathophysiologically characterized by a profound damage to the alveolar-capillary barrier due to injury, resulting in overflooding of the alveolar space, causing an impossibility of an adequate gas exchange [2, 3].

ARDS accounts for an average of $10.4 \%$ of all intensive care unit (ICU) admissions [5] with mortality ranging between $34.9 \%$ in mild cases to up to $46.1 \%$ in those 
with severe ARDS [5] as defined according to the Berlin definition [6] (Fig. 1). In survivors, quality of life is severely impaired [7], causing unsustainable human and economic burden. Considering the significant impact in health and economical terms, major research efforts have been conducted in the past 5 decades to more accurately characterize ARDS pathophysiology and to find an effective treatment. Unfortunately, research thus far has been largely unsuccessful in providing conclusive evidence of treatments that provide improved outcomes $[8,9]$, aside from supportive care to reduce ARDS mortality [8]. Consequently, regardless of the etiology or severity, ARDS patients are currently treated in a homogenous fashion [10].

However, it has to be emphasized that a good proportion of interventional studies evaluating treatment options in ARDS were conducted before the dogma change in mechanical ventilation toward lung-protective strategies [11]. Since it is now known that a non-protective ventilation strategy causes an additional inflammatory reaction [12, 13], a potential benefit of these applied treatments may therefore have been masked. Considering that the human ARDS population is highly heterogenous, it seems very likely that a uniform therapy non-selectively applied to all patients may further dilute any potential effect. These two factors could have been the main culprit of failure in previous studies.

This narrative review aims to provide an overview of the state of the current evidence in biological subphenotyping in ARDS regarding identified features, mortality rates, and different reaction to medical measures and treatment among patient subgroups. Additionally, we aim to identify important gaps in current knowledge that are to overcome in order to move forward in using biological subphenotyping in ARDS in future trials. This review focuses on biological subphenotyping only as this approach seems to be the most promising one for enrichment strategies in future ARDS trials.

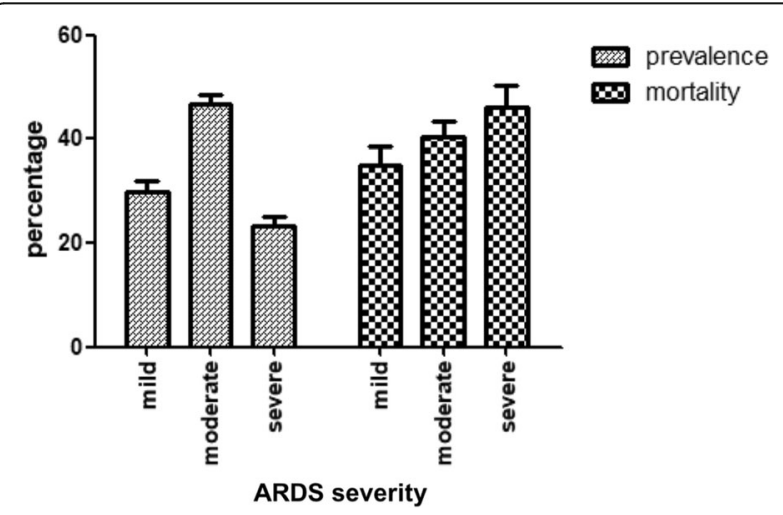

Fig. 1 Mortality in ARDS according to the severity as defined by $\mathrm{PaO}_{2} / \mathrm{FiO}_{2}$-ratio

\section{Approaches to subphenotyping in ARDS}

A subphenotype is defined as a subgroup among a disease entity that (a) is at highest risk for poor outcome (prognostic enrichment) or (b) shares similar underlying biological factors and/or a different reaction to medical measures (predictive enrichment) [14, 15] (Fig. 2). Enrichment strategies offer the potential to reduce heterogeneity and hence allow an approach to precision medicine by selecting the subgroup most likely to benefit [16].

Over the years, there have been several attempts to define subgroups among ARDS, either by differentiation according to the inflicting cause of ARDS as direct or indirect pulmonary injury $[17,18]$ or by confining traumarelated ARDS as this seemed to display different biological features [19, 20]. The Berlin definition [6] itself provides a prognostic enrichment as it divides the ARDS population into three severity subphenotypes according to the $\mathrm{PaO} 2$ to $\mathrm{FiO} 2$ ratio (PF ratio) with discriminative mortality rates [5]. From autopsy studies, we learnt about the presence of diffuse alveolar damage (DAD) [21-23], that was mainly found in moderate to severe ARDS [23] indicating a specific biological mechanism. Imaging studies reported that ARDS patients with diffuse radiological patterns displayed a higher mortality as compared to patients with focal patterns [24, 25]; these findings were associated with differences in pulmonary mechanics [26] but failed to result in different outcomes when applying a targeted ventilation approach [27].

All these subphenotyping attempts helped us clinicians to gain understanding about the complex syndrome of ARDS but were ultimately shown a weak or complete lack of evidence for a different treatment response or improved outcomes, most likely because underlying biological factors are yet to be completely understood. The novel concept of biological subphenotyes, two distinct subphenotypes, defined by specific functional and biological parameters, offers a novel and potentially more targeted approach to the very heterogenous population of ARDS. These biological subphenotypes were identified by latent class analysis (LCA), a novel statistical method for identifying unmeasured class membership among subjects, assuming that the data contains a certain number of unobserved groups (or classes). LCA uses an iterative algorithm by using mixture modeling, that identifies the best fit of number of classes between 1 and $\mathrm{n}$ for a data set and assigns each subject to a specific class [28, 29].

\section{The cornerstone of biological subphenotyping in ARDS}

The origin of this new approach to ARDS was implemented in 2014 by Calfee et al. [30]. The group retrospectively analyzed two randomized controlled trials 


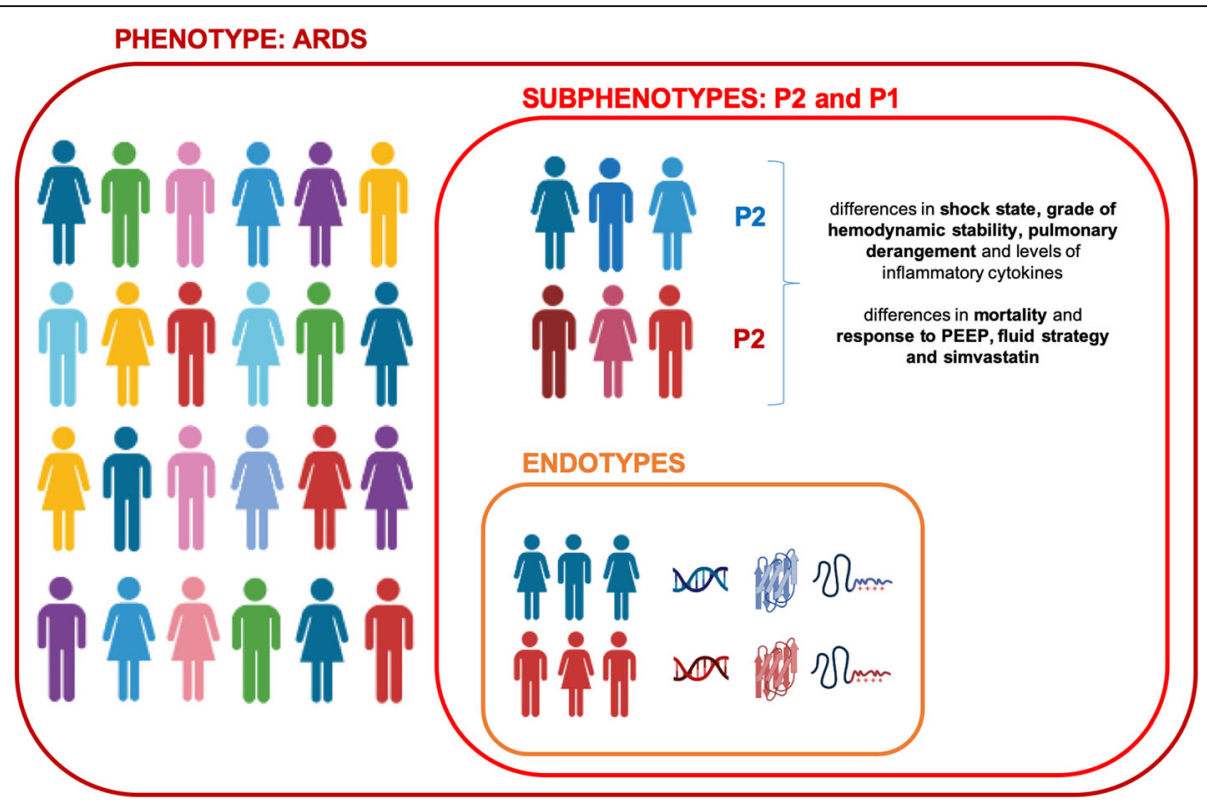

Fig. 2 A phenotype denotes a group of patients that share a common syndrome, ARDS in this case. A subphenotype is a subset of patients within the phenotype that share specific features, such as clinical variables, outcomes, or responses to treatment or medical measures, that clearly differentiates this subgroup from others. An endotype is defined as a subgroup of patients within the subphenotype that have distinct biological mechanisms of the syndrome in common, such as gene expression and activated molecular pathways. For now, the definition of endotypes in ARDS is purely hypothetical as we know little about underlying biology

(RCT) from the National Heart Lung and Blood Institute (NHLBI) ARDS Network by LCA: the ARMA trial (Ventilation with Lower Tidal Volumes as Compared with Traditional Tidal Volumes for Acute Lung Injury and the Acute Respiratory Distress Syndrome) [11] that contributed 473 patients from the low tidal volume (VT) ventilation group (429 patients with high VT's were excluded) and the ALVEOLI trial (Assessment of Low tidal Volume and elevated End-expiratory volume to Obviate Lung Injury) [31] which assessed different positive end expiratory pressure (PEEP) settings and contributed 549 patients to this analysis. Blood samples were taken at the time of randomization, $<36 \mathrm{~h}$ since fulfilling ARDS criteria. In the ARMA population as the derivation cohort, a two-class model was found to be the best fit and divided the population into a hyperinflammatory (named P2) and a hypoinflammatory subphenotype (named P1). One-third of patients were assigned to P2 (Fig. 3), with a significantly higher fraction of these patients being in shock. Dominant discriminating biomarkers were Interleukin (IL)-6 and -8, soluble tumor necrosis factor receptor 1 (sTNFR1), plasminogen activator inhibitor-1 (PAI-1), intercellular adhesion molecule-1 (ICAM-1), von Willebrand factor (vWF), bilirubin, bicarbonate, protein $\mathrm{C}(\mathrm{PC}), \mathrm{PaCO}_{2}$, platelets, albumin, and glucose. The clinical variables heart rate, minute ventilation, vasoactive use, plateau pressure, PEEP, and systolic blood pressure were shown to discriminate best between the subphenotypes (Table 1). Interestingly, neither the severity of ARDS as defined by the $\mathrm{PaO}_{2} / \mathrm{FiO}_{2}$ ratio (PF) [6], the severity of renal or hepatic failure, nor the extent of leukocytosis distinguished the two subphenotypes from each other. Risk factors for P2 were sepsis, pneumonia, and aspiration (in decreasing order), whereas in P1 it was pneumonia, sepsis, and aspiration. In comparison with the hypoinflammatory subphenotype, P2 displayed a higher 90 -day mortality (44\% vs. $23 \%, p=$ 0.006 ) (Fig. 3) and significantly less organ failure-free (9.8\% vs. $16.8 \% ; p<0.001)$ as well as ventilator-free days (9.1\% vs. $14.0 \% ; p<0.001)$. The same results were confirmed in the ALVEOLI cohort with remarkably similar characteristics of subphenotypes. Regarding outcome, the difference in 90-day mortality was even more pronounced with $51 \%$ and $19 \%$ in the P2 and P1 subgroups, respectively $(p<0.001)$ (Fig. 3$)$.

The FACTT trial (Fluid and Catheter Treatment Trial) [32] was another NHLBI-promoted study, randomizing ARDS patients in a two-by-two factorial design into 2 study arms for comparing fluid-liberal versus fluidrestrictive volume strategy and monitoring with pulmonary artery catheter versus central venous catheter, respectively. No difference in mortality at 60 days was found with either intervention, but significantly more ventilator-free days occurred in patients randomized to the fluid-conservative group. Famous et al. [33] analyzed the 1000 included patients retrospectively and found again that a 2-class model was the best fit, with $27.2 \%$ of patients assigned to P2 and $72.8 \%$ to P1 (Fig. 3). Best 

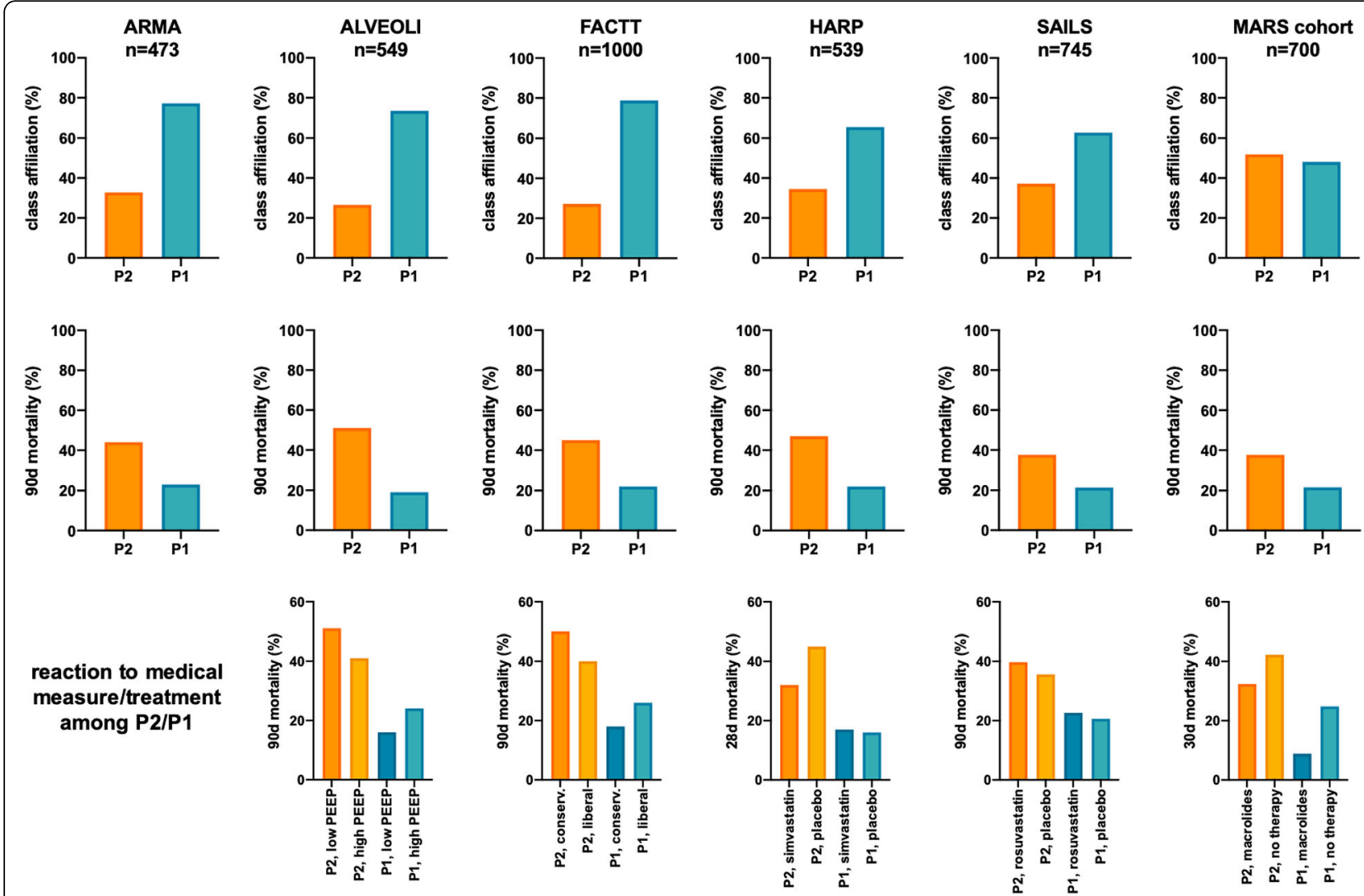

Fig. 3 Class assignment to subphenotypes of ARDS, associated 90-day mortality and mortality according to different treatment. ARMA acute respiratory management of acute lung injury, ALVEOLI assessment of low tidal volume and elevated end-expiratory volume to obviate lung injury, MARS molecular diagnosis and risk stratification of sepsis, FACTT fluid and catheter treatment trial, SAlLS statins for acutely injured lungs from sepsis, HARP hydroxymethylglutaryl-CoA reductase inhibition with simvastatin in acute lung injury to reduce pulmonary dysfunction, PEEP positive end-expiratory pressure, $P 2$ hyperinflammatory subphenotype, $P 1$ hypoinflammatory subphenotype

discriminating biomarkers in this cohort were once again IL-8 and -6, PAI-1, vWF, bilirubin, bicarbonate, $\mathrm{PC}, \mathrm{PaCO}_{2}$, platelets, albumin, but also TNFr-1, angiopoetin-2 (Ang-2), receptor for advanced glycation endproducts (RAGE), and creatinine. In terms of clinical variables, heart rate, minute ventilation, airway pressures, vasoactive use, PEEP, and systolic blood pressure distinguished most accurately between subphenotypes. These findings were later validated in the ARMA and ALVEOLI cohorts. Again, 90-day mortality was significantly higher in P2 than P1 with $45 \%$ and $22 \%$ respectively (Fig. 3). Sepsis was a risk factor for ARDS in P2 subphenotype in $53 \%$, whereas trauma, aspiration, and pneumonia were more likely in P1.

\section{The proof of stable class assignment over time}

In order to understand the pathogenesis of subphenotypes in ARDS, knowledge about stability of subphenotypes over time is crucial. This task was accomplished by Delucchi et al. [34] in the ARMA and ALVEOLI cohorts through analysis on day 0 and 3 with a latent transition model. Authors founds evidence for stable classes over the first 3 days with the majority of patients being in the same class at day 0 and day 3 respectively. Only $5 \%$ of patients had a change in class (more frequently from P1 to P2), whereas the clinical outcome was associated with the later class. These important findings add further evidence to the hypothesis that there are fundamental biological and clinically relevant differences in subphenotypes in ARDS, concluding that these are not manifestations of different stages of the same disease as the subphenotype patterns are not affected by the measurement time point.

\section{The validation of ARDS subphenotypes in two European cohorts}

Bos et al. 2017 [35] chose hierarchical clustering as an approach for the analysis of the MARS cohort (Molecular Diagnosis and Risk Stratification of Sepsis), a biobank initiative in sepsis, conducted in 2 ICU's in the Netherlands between 2011 and 2013. In this analysis, ARDS was clustered according to biomarkers only and then associated with outcome. A total of 700 patients were available for analysis, divided in 454 for the training 
Table 1 Characteristics of retrospectively assessed ARDS studies regarding ARDS subphenotypes: study design, analysis method, mortality, reaction to treatment, clinical variables, and biomarkers that differentiated best between subphenotypes of ARDS

\begin{tabular}{|c|c|c|c|c|c|c|}
\hline & Country & $\begin{array}{l}\text { Study design and } \\
\text { analysis } \\
\text { methodAnalysis } \\
\text { method }\end{array}$ & $\begin{array}{l}\text { 90-day } \\
\text { mortality }\end{array}$ & $\begin{array}{l}\text { Evaluation of } \\
\text { reaction among } \\
\text { P2/P1 to }\end{array}$ & Clinical variables & Blood parameters \\
\hline $\begin{array}{l}\text { ARMA, } n \\
=473 \\
\text { ALVEOLI, } \\
n=549\end{array}$ & $\begin{array}{l}\text { USA } \\
\text { (NHLBI) }\end{array}$ & $\begin{array}{l}\text { RCT } \\
\text { LCA }\end{array}$ & $\begin{array}{l}\text { ARMA } \\
\text { P2 44\% } \\
\text { P1 23\% } \\
\text { ALVEOLI } \\
\text { P2 51\% } \\
\text { P1 22\% }\end{array}$ & $\begin{array}{l}\text { ALVEOLI: } \\
\text { application of } \\
\text { PEEP }\end{array}$ & $\begin{array}{l}\text { Circulatory: heart rate, } \mathrm{BPm}, \\
\text { vasoactive use } \\
\frac{\text { Respiratory: minute ventilation, }}{\text { Pplat, PEEP }}\end{array}$ & $\begin{array}{l}\text { Inflammation: IL-6, IL-8, sTNFR-1, } \\
\text { CRP, WCC } \\
\text { Coagulation: PAI-1, protein C, } \\
\text { platelets } \\
\text { Endothelial: Ang-2, ICAM-1, vWF } \\
\text { Others: bilirubin, bicarbonate, } \\
\text { PaCO }_{2} \text {, albumin, glucose }\end{array}$ \\
\hline $\begin{array}{l}\text { MARS, } n \\
=700\end{array}$ & $\mathrm{NL}$ & $\begin{array}{l}\text { Observational cohort } \\
\text { Clustering methods }\end{array}$ & $\begin{array}{l}\text { P2 } 37.7 \% \\
\text { P1 } 21.6 \%\end{array}$ & $\begin{array}{l}\text { Macrolide } \\
\text { Antibiotics }\end{array}$ & None & $\begin{array}{l}\frac{\text { Inflammation: IL-6, IL-8, IL-10, IFN- }}{\text { Y }} \\
\text { Enothelial: Ang-1, Ang-2 } \\
\text { Coagulation: PAI-1, antithrombin }\end{array}$ \\
\hline $\begin{array}{l}\text { FACTT, } n \\
=1000\end{array}$ & $\begin{array}{l}\text { USA } \\
\text { (NHLBI) }\end{array}$ & $\begin{array}{l}\text { RCT } \\
\text { LCA }\end{array}$ & $\begin{array}{l}\text { P2 45\% } \\
\text { P1 22\% }\end{array}$ & Fluid strategy & $\begin{array}{l}\text { Circulatory: heart rate, BPs, } \\
\text { vasoactive use } \\
\text { Respiratory: minute ventilation, } \\
\text { airway pressure, PEEP }\end{array}$ & $\begin{array}{l}\text { Inflammation: IL-6, IL-8, TNFR-1, } \\
\text { IFN-y } \\
\text { Coagulation: PAI-1, protein C, } \\
\text { platelets } \\
\text { Endothelial: Ang-2, vWF } \\
\text { Lung epithelial: RAGE } \\
\text { Others: bilirubin, bicarbonate, } \\
\text { creatinine, PaCO } \\
\text { glucose, albumin, } \\
\text { glucose }\end{array}$ \\
\hline $\begin{array}{l}\text { SAILS, } n \\
=745\end{array}$ & $\begin{array}{l}\text { USA } \\
\text { (NHLBI) }\end{array}$ & $\begin{array}{l}\text { RCT } \\
\text { LCA }\end{array}$ & $\begin{array}{l}\text { P2 } 37.6 \% \\
\text { P1 } 21.4 \%\end{array}$ & Rosuvastatin & $\begin{array}{l}\text { Circulatory: heart rate, BPs, } \\
\text { vasoactive use } \\
\text { Respiratory: minute ventilation, } \\
\text { respiratory rate, pulmonary risk } \\
\text { factors } \\
\text { others: urinary output }\end{array}$ & $\begin{array}{l}\text { Inflammation: IL-6, IL-8, sTNFR-1, } \\
\text { WCC } \\
\text { Coagulation: protein C, platelets, } \\
\text { PAl-1, platelets } \\
\text { Endothelial: ICAM-1 } \\
\text { Others: bilirubin, bicarbonate, } \\
\text { creatinine, } \mathrm{PaCO}_{2} \text {, albumin, } \\
\text { glucose }\end{array}$ \\
\hline $\begin{array}{l}\text { HARP, } n \\
=539\end{array}$ & UK/IR & $\begin{array}{l}\text { RCT } \\
\text { LCA }\end{array}$ & $\begin{array}{l}\text { P2 } 47 \% \\
\text { P1 } 22 \%\end{array}$ & Simvastatin & $\begin{array}{l}\text { Circulatory: vasoactive use } \\
\text { Pulmonary: PF ratio }\end{array}$ & $\begin{array}{l}\text { Inflammation: IL-6, sTNFR-1 } \\
\text { Coagulation: platelets } \\
\text { Others: creatinine, bilirubin }\end{array}$ \\
\hline $\begin{array}{l}\text { Kitsios } \\
\text { et al., } n= \\
212\end{array}$ & $\begin{array}{l}\text { USA } \\
\text { (NHLBI) }\end{array}$ & $\begin{array}{l}\text { Observational cohort } \\
\text { LCA }\end{array}$ & $\begin{array}{l}\frac{\text { ARDS }}{\text { P2 44\% }} \\
\text { P1 22\% } \\
\text { ARFA } \\
\text { P2 53 } \% \\
\text { P1 18\% }\end{array}$ & None & $\begin{array}{l}\text { Circulatory: } \mathrm{BPs} \text {, heart rate } \\
\text { Pulmonary: PEEP, Pplat, PF } \\
\text { ratio, respiratory rate, PF ratio } \\
\underline{\text { Others: temperature }}\end{array}$ & $\begin{array}{l}\text { Inflammation: IL-6, IL-8, IL-10, } \\
\text { TNFR-1, WCC, PCT } \\
\text { Coagulation: protein C, platelets } \\
\text { Endothelial: ICAM-1, Ang-2 } \\
\text { Lung epithelial: RAGE } \\
\text { Others: Creatinine, PaCO } \\
\text { fractalkine, pentraxin3, pH art }\end{array}$ \\
\hline
\end{tabular}

ARMA Acute Respiratory Management of Acute lung injury, ALVEOLI assessment of low tidal volume and elevated end-expiratory volume to obviate lung injury, MARS Molecular diagnosis and risk stratification of sepsis, FACTT Fluid and Catheter Treatment Trial, SAlLS statins for acutely injured lungs from sepsis, HARP hydroxymethylglutaryl-CoA reductase inhibition with simvastatin in acute lung injury to reduce pulmonary dysfunction, RCT randomized controlled trial, $L C A$ latent cluster analysis, $P 2$ hyperinflammatory subphenotype, $P 1$ hypoinflammatory subpenotype, $A R F A$ at risk for ARDS, $B P m$ mean blood pressure, $B P s$ systolic blood pressure, Pplat plateau pressure, PEEP positive end-exspiratory pressure, IL interleukin, sTNFR-1 soluable tumor necrosis factor receptor-1, CRP C-reactive protein, WCC white cell count, PAI-1 plasminogen inhibitor-1, Ang-1/-2 angiopoetin-1/-2, ICAM-1 intracellular adhesion molecule-1, vWF von Willebrand factor, $P a C O_{2}$ arterial $\mathrm{CO}_{2}$ partial pressure, IFN- $\gamma$ interferon gamma, RAGE receptor for advanced glycation end-products, $P F$ ratio $\mathrm{PaO}_{2} / \mathrm{FiO}_{2}$ ratio; ST-2 suppression of tumorigenicity, $P C T$ procalcitonin

and 246 patients for the validation group. A reactive and an uninflamed subphenotype was defined with an ICU mortality of $36.4 \%$ and $15.6 \%$ accordingly (Fig. 3). The reactive subphenotype was characterized by higher Acute Physiology and Chronic Health Evaluation scores (APACHE), more severe multi-organ failure and indirect causes of ARDS. The dominant discriminant biomarkers between the two subphenotypes were IL-6, -8, -10, interferon-gamma (IFN $\gamma$ ), Ang-1/-2, and PAI-1 (Table 1). A 5-factor model, consisting of IL-6, IFN- $\gamma$, Ang-1/2, and PAI-1, provided an area under the curve (AUC) of 0.98
(95\%CI 0.97 to 0.99 ) for discrimination between subphenotypes. Even though the class assignment to the reactive subpenotype was twice as high than reported previously $[30,33,34]$, mortality and defining biomarkers of the two subphenotypes were quite comparable, suggesting that a similar cluster exists across all these cohorts. The difference in prevalence may be explained by a selection bias in RCT`s or underlying biological factors.

The HARP-2 trial (hydroxymethylglutaryl-CoA (HMG-CoA) reductase inhibition with simvastatin in acute lung injury to reduce pulmonary dysfunction) [36] 
was a multicenter RCT of simvastatin daily versus placebo in ARDS, conducted in 40 ICUs in the UK and Ireland over 4 years, randomizing 540 patients. No significant difference was detected between the study groups regarding 28-day mortality or number of ventilator-free days in the original study. Yet, in a secondary analysis by Calfee et al. [37], a 2-class model was again the best fit: $65 \%$ of patients were assigned to P1 and $35 \%$ to P2 subphenotype (Fig. 3). The best discriminating variables were sTNFR-1, creatinine, IL-6, bilirubin, platelets, vasoactive use, and the PF-ratio (Table 1). P2 experienced less ventilator-free days (2 vs. 18 days), fewer non-pulmonary organ failure-free days (15 vs. 27 days), and a higher 90 -day mortality (47 vs. $22 \%$; all $p<$ 0.001) than the P1 subphenotype (Fig. 3). The most common ARDS risk factors sepsis, pneumonia, and aspiration were highly prevalent in both groups.

\section{Findings from the SAILS cohort}

As another 3-HMG-CoA-reductase inhibitor, rosuvastatin was tested versus placebo for its efficacy in ARDS in the SAILS study (Statins for Acutely Injured Lungs from Sepsis). In this NHLBI ARDS Network trial in infectionassociated ARDS [38], including 745 patients between 2010 and 2013, no difference in mortality was found between the groups. The SAILS cohort was retrospectively analyzed [39], using LCA for clinical variables and biomarkers, and consistently, a two-class model was found to be the best fit. Further, 227 patients (37\%) were assigned to $\mathrm{P} 2$ and 448 patients (63\%) to the P1 subphenotype. The 60 -day mortality of $36.5 \%$ and the 90 -day mortality of $37.6 \%$ was significantly higher in the P2 group than in the patient group assigned to P1 (20.9\% and $21.4 \%$ respectively, all comparison $p<0.0001$ ) (Fig. $3)$. Furthermore, the P2 group experienced fewer ventilator-free days (15 vs. 23 days; $p<0.0001)$. The class defining features were consistent with the previous analysis of the three NHLBI cohorts (ARMA, ALVEOLI, FACTT): IL-6 and -8, sTNFR-1, ICAM-1, PAI-1, PC, $\mathrm{PaCO}_{2}$, platelets, bicarbonate, albumin, bilirubin, creatinine, systolic blood pressure, heart and respiratory rate, vasoactive use, minute ventilation (Table 1). In addition, the P2 group had a higher white cell count, lower urinary output, and more pulmonary risk factors for ARDS. Also consistently with the results from the NHLBI ARDS Network datasets, respiratory variables including the PF-ratio performed poorly in discriminating between classes. The prominence of biomarkers as class defining variables suggests that subphenotypes may primarily be governed by basic biological factors. The authors concluded that these 4 NHLBI ARDS network datasets consistently reveal the same subphenotypes. This underlines their contemporaneous relevance despite changing demographical patterns and clinical practice in ARDS [40]. The replication of the results in ARDS cohorts from the UK/ Ireland [37] and the Netherlands [35] proves the robustness and generalizability of the subphenotype model intercontinentally.

\section{Different reaction to medical measures among the subphenotypes}

By analyzing the ALVEOLI cohort, a significant interaction between class assignment and PEEP settings as medical intervention was noted [30]. The P2 subphenotype displayed a 90 -day mortality rate of $51 \%$ with low PEEP and of $40 \%$ with high PEEP, whereas in P1 the mortality rate of the two PEEP settings was $16 \%$ and $24 \%(p=0.049)$ (Fig. 3). An even stronger interaction was seen between subphenotype and PEEP strategy regarding ventilator-free and organ failure-free days, where the P2 with a high-PEEP strategy showed significantly lower numbers for both outcomes. The authors concluded that the significant differences in natural histories, clinical, and biological characteristics as well as outcomes and response to treatment among the two different ARDS subphenotypes are characteristic requirements that have to be fulfilled to define a subphenotype.

In contra distinction to the findings of the original FACTT cohort as outlined above, differences in 90-day mortality relating to the applied fluid strategy were identified in the two identified subphenotypes [33]: P1 had a higher mortality with liberal compared to conservative fluid management (26 vs. $18 \%$ ) and P2 was shown a higher mortality with conservative compared to liberal fluid management (50 vs. 40\%) (Fig. 3).

De Simonis et al. [41] analyzed the MARS cohort regarding a treatment effect of macrolide antibiotics on subphenotypes using propensity-score (PS) matching. Then, 715 patients without macrolides were 3/1matched to 158 patients with macrolide treatment (97\% erythromycin). Most patients were treated within 5 days of ARDS diagnosis for a total of 3 days. Overall, patients with macrolides had an odds ratio for mortality of 0.64 $(p=0.03)$; this remained significant after PS-matching. The mortality at 30 days was specifically lower in nonpulmonary ARDS after PS-matching and in the P1 subphenotype before and after PS-matching (Fig. 3). The authors concluded that the effect was most probably mediated through a reduction in cytokines and an effect on neutrophil granulocytes.

Although the HARP-2 trial showed no difference in adjudicated outcomes, the secondary analysis [37] identified a different response to simvastatin when splitting the cohort into subphenotypes: P2 patients treated with simvastatin had a lower 28-day mortality with $32 \%$ (27/ $84)$ vs. $45 \%(46 / 102)(p=0.008)$ in the placebo group. This was not observed in P1 where the 28-day mortality 
was $17 \%$ in the treatment group and $16 \%$ in the placebo group ( $p=$ ns) (Fig. 3).

Interestingly, in the SAILS cohort [39] as opposed to HARP-2, there was no difference in all three outcome measures in the P2 subphenotype regarding treatment with rosuvastatin (Fig. 3). While SAILS assessed infection-related ARDS, HARP-2 included a much wider variety of ARDS risk factors, therefore the identified subphenotypes may differ between the two cohorts. In addition, it was postulated that the use of a different 3HMG-reductase inhibitor might explain the difference in outcome: while simvastatin is a lipophilic molecule with some clinical evidence in lung injury [42], rosuvastatin is hydrophilic with known different influence on plasma levels of inflammation markers [43]. Therefore, the use of a hydrophilic statin may be responsible for the negative results in the retrospective analysis of the SAILS dataset.

\section{Subphenotypes in patients at risk for ARDS?}

In a recent publication [44], LCA was applied to baseline clinical variables and biomarkers in patients with ARDS as well as in patients at risk for ARDS (ARFA) but not entirely fulfilling the diagnostic criteria. Interestingly, a two-class model provided the best fit in both patient groups, whereas 38\% (39/104) of ARDS and 28\% (30/ 108) of ARFA patients were assigned to the hyperinflammatory subphenotype. The differentiating variables between the subphenotypes were comparable to the ones previously reported (Table 1). Both, hyperinflammatory ARDS and ARFA, were shown a higher 90-day mortality than hypoinflammatory subphenotypes ( $44 \%$ vs. $33 \%$ and $53 \%$ vs. $18 \%$ ) but statistical significance was only reached in ARFA. These findings suggest that likely the extent of subphenotypes is not restricted to fully developed ARDS but are already present in preliminary stages due to similar driving factors.

\section{The gaps in the current knowledge}

All these outlined results underline that most likely similar subphenotypes are observed among ARMA, ALVEOLI, FACTT, and SAILS, as well as among HARP-2 and the MARS cohort, which highlights the generalizability of subphenotypes among varying ARDS populations. Although these recent developments in ARDS research are very exciting and promising, there are still major challenges to overcome.

First, the underlying driving biological factors are still largely unknown. The key to a more thoroughly understanding may lay in omics data generation and application $[45,46]$. Analyzing leukocyte expression profiles in the MARS cohort [47] was the first attempt to more fully understand molecular pathways in subpenotypes in ARDS by comparing differential gene expression that might be indicative of pathophysiologic changes within the subphenotype. The respective subphenotype was identified by the 5 -factor-model [35] as previously derived in the MARS dataset [35]. Among 210 patients, 82 $(38 \%)$ were assigned to the uninflamed (P1) and 128 (62\%) patients to the reactive/hyperinflammatory subphenotype (P2). These were compared to 547 patients with sepsis but no ARDS and 42 healthy age-matched controls. Twenty-nine percent $(3332 / 11443)$ of genes were significantly differently expressed between subphenotypes. In P2, 7 of 8 genes previously positively associated with ARDS [48], were shown to be upregulated, with pathways of oxidative phosphorylation (indicative of mitochondrial dysfunction) as well as cholesterol metabolism and the innate immune system being the most enriched ones. Fifty percent of genes that were previously found to be negatively associated with ARDS were upregulated in P1. Specifically, pathways coordinating cell proliferation and differentiation, motility and survival as well as the adaptive immune system were enriched in P1. Interestingly, sepsis patients without ARDS were most similar to P1 subphenotypes expression. While these results provide a glimpse to potential revelation of different underlying biological factors, we are still far away from an in-depth understanding. Previous studies with whole blood gene expression studies failed to prove a consistent gene signature for ARDS patients [49], assumingly because of a mixture in ARDS subphenotypes. In the near future, bioinformatic approaches like genomics, proteomics, transcriptomics and metabolomics will enhance our understanding of driving factors on a molecular level.

The second significant gap inhibiting current clinical application lies in the lack of an reliable and easy to use biomarker for differentiation between subphenotypes at the bedside. A first attempt at solving this hindrance was recently published [50]. Machine learning algorithms were applied to 3 cohorts from the NHLBI ARDS Network (ARMA, ALVEOLI, FACTT) incorporating 2200 patients, to select the six most important classifier variables for development of nested logistic regression models. The logistic regression models with the highest predictive accuracy were then evaluated in the validation cohort (SAILS; $n=715$ ). The most important classifier factors were IL-8, -6, PC, sTNFR-1, bicarbonate and vasoactive use. A 4-variable model, incorporating IL-8, bicarbonate, $\mathrm{PC}$, and vasoactive use, resulted in an AUC of $0.95(95 \% \mathrm{CI}$ 0.93-0.96) and performed best as compared with the LCA classification as the gold standard. Similar to the LCAderived subphenotypes, P2 derived from the classifier model was shown to have a higher 90-day mortality than P1 (39\% vs. $23 \%, p<0.0001)$ and fewer ventilator-free days. However promising, so far there is no point-of-care test to identify subphenotypes in the clinical setting. 
Third, even if there was a bedside test to select a specific subphenotype, the resulting clinical relevance is yet to be determined since the retrospective data have shown conflicting results regarding a treatment benefit in one specific ARDS subphenotype [37, 39, 41].

Fourth, the extent and clinical relevance of subphenotypes beyond ARDS has to be determined. The results by Kitsios et al. [44] are promising as we start to suspect that the true extent of subphenotypes is much larger than assumed and not only related to hypo- or hyperinflammatory states and maybe not even limited to lung failure $[51,52]$. Validation in a larger cohort of patients with heterogenous risk factors for ARDS and a model to predicate its stability is needed.

Within the coming years, very likely we will have a more in-depth understanding of underlying disease mechanisms. The key to successfully translate this knowledge will lay in predictive enrichment [14, 53], meaning that reducing heterogeneity and thereby improving trial efficiency by refining patient selection and choosing patients more likely to respond to drug treatment will facilitate personalized medicine in this field and increase absolute and relative effects, as it has been shown previously [54-58].

\section{Conclusion}

The clinical and biological heterogeneity of the ARDS population continues to gain acceptance in the clinical community, and might explain the five decades of ARDS research without treatment success. Subphenotyping provides a new promising approach for therapeutic development through the concept of predictive and prognostic enrichment, potentially resulting in a more targeted treatment. Nevertheless, there are crucial gaps yet to overcome, namely a more in-depth understanding of the underlying driving biological factors and a reliable biomarker for early differentiation between subphenotypes at the bedside. Once these hindrances have been resolved, subphenotyping will most likely be the key factor in all future pursuits in ARDS treatment.

\footnotetext{
Abbreviations

ALVEOLI: Assessment of Low tidal Volume and elevated End-expiratory volume to Obviate Lung Injury; Ang-1/-2: Angiopoetin-1/-2; APACHE: Acute Physiology and Chronic Health Evaluation score; ARDS: Acute respiratory distress syndrome; ARFA: At risk for ARDS; ARMA: Ventilation with Lower Tidal Volumes as Compared with Traditional Tidal Volumes for Acute Lung Injury and the Acute Respiratory Distress Syndrome; AUC: Area under the curve; DAD: Diffuse alveolar damage; FACTT: Fluid and Catheter Treatment Trial; HARP-2: Hydroxymethylglutaryl-COA Reductase inhibition with simvastatin in acute lung injury to reduce Pulmonary dysfunction; HMGCoA: Hydroxymethylglutaryl-COA; ICAM-1: Intercellular adhesion molecule-1; ICU: Intensive Care Unit; IFNy: Interferon-y; IL: Interleukin; LCA: Latent cluster analysis; MARS: Molecular Diagnosis and Risk Stratification of Sepsis; NHLBI: National Heart Lung and Blood Institute; $\mathrm{PaCO}_{2}$ : Arterial $\mathrm{CO}_{2}$ partial pressure; $\mathrm{PaO}_{2}$ : Arterial $\mathrm{O}_{2}$ partial pressure; PAl-1: Plasminogen activator inhibitor-1; PC: Protein C; PEEP: Positive end-expiratory pressure; PF ratio: $\mathrm{PaO}_{2} / \mathrm{FiO}_{2}$ ratio; $\mathrm{P} 1$ : Uninflamed or hypoinflammatory subphenotype;
}

P2: Hyperinflammatory or reactive subphenotype; PS: Propensity score; RAGE: Receptor for advanced glycation endproducts; RCT: Randomized controlled trial; SAILS: Statins for Acutely Injured Lungs from Sepsis; (s)TNFr1: (Soluble) tumor necrosis factor receptor-1; VT: Tidal volume; VWF: Von Willebrand factor

\section{Acknowledgements}

Not applicable.

\section{Authors' contributions}

All listed made substantial contributions to draft the work and approved the final version for publication.

\section{Authors' information}

Not applicable.

\section{Funding}

Dr. Wildi has received research funding from the FAG Basel, the Julia und Gottfried Bangerter-Rhyner Stiftung, the Prince Charles Hospital Foundation, the Wesley Medical Research Foundation and the CRE Action Fund (NHMRC). In addition, she received a PhD scholarship from the University of Queensland. Samantha Livingstone received a PhD scholarship of the Prince Charles Foundation. A/Prof. LiBassi has received research funds, through his affiliated institution from Fisher \& Paykel. Dr. Suen has receiced an Advance Queensland Industry Research Fellowship and Prof. John Fraser received a fellowship from the Queensland Department of Health.

\section{Availability of data and materials}

Not applicable.

Ethics approval and consent to participate Not applicable.

Consent for publication

Not applicable.

\section{Competing interests}

There are no competing interests related to this work.

\section{Author details}

${ }^{1}$ The Critical Care Research Group, The Prince Charles Hospital, Clinical Sciences Building, Level 3, Chermside, Brisbane, QLD 4032, Australia. ${ }^{2}$ Faculty of Medicine, The University of Queensland, Brisbane, Australia.

${ }^{3}$ Cardiovascular Research Group, Basel, Switzerland. ${ }^{4}$ School of Veterinary

Science, the University of Queensland, Brisbane, Australia.

Received: 7 December 2020 Accepted: 11 January 2021

Published online: 21 January 2021

\section{References}

1. Ashbaugh DG, Bigelow DB, Petty TL, Levine BE. Acute respiratory distress in adults. Lancet. 1967;2(7511):319-23.

2. Mac SR, DF MA. Acute respiratory distress syndrome. Lancet. 2016;388: 2416-30.

3. Ware LB, Matthay MA. The acute respiratory distress syndrome. N Engl J Med. 2000;342(18):1334-49.

4. Pelosi P, Caironi P, Gattinoni L. Pulmonary and extrapulmonary forms of acute respiratory distress syndrome. Semin Respir Crit Care Med. 2001; 22(03):259-68

5. Bellani G, Laffey JG, Pham T, Fan E, Brochard L, Esteban A, et al. Epidemiology, patterns of care, and mortality for patients with acute respiratory distress syndrome in intensive care units in 50 Countries. JAMA. 2016;315(8):788-800.

6. Ranieri VM, Rubenfeld GD, Thompson BT, Ferguson ND, Caldwell E, Fan E, et al. Acute respiratory distress syndrome: the Berlin Definition. J Am Med Assoc. 2012;307(23):2526-33.

7. Herridge MS, Tansey CM, Matté A, Tomlinson G, Diaz-Granados N, Cooper A, et al. Functional disability 5 years after acute respiratory distress syndrome. N Engl J Med. 2011;364(14):1293-304. 
8. Santacruz CA, Pereira AJ, Celis E, Vincent J. Which multicenter randomized controlled trials in critical care medicine have shown reduced mortality? A Systematic Review Crit Care Med. 2019;47(12):1680-91.

9. Fan E, Brodie D, Slutsky AS. Acute respiratory distress syndrome: advances in diagnosis and treatment. J Am Med Assoc. 2018;319(7):698.

10. Griffiths MJD, McAuley DF, Perkins GD, Barrett N, Blackwood B, Boyle A, et al. Guidelines on the management of acute respiratory distress syndrome. BMJ Open Respir Res. 2019;6(1):e000420.

11. The ARDS. Network. Ventilation with lower tidal volumes as compared with traditional tidal volumes for acute lung injury and the acute respiratory distress syndrome. N Engl J Med. 2000;342(18):1301-8.

12. Petrucci $N$, De Feo C. Lung protective ventilation strategy for the acute respiratory distress syndrome. Cochrane Database Syst Rev. 2013;3: CD003844.

13. Putensen C. Meta-analysis: ventilation strategies and outcomes of the acute Respiratory distress syndrome and acute lung injury. Ann Intern Med. 2009; 151(8):566.

14. Prescott HC, Calfee CS, Thompson BT, Angus DC, Liu VX. Toward smarter lumping and smarter splitting: rethinking strategies for sepsis and acute respiratory distress syndrome clinical trial design. Am J Respir Crit Care Med. 2016;194(2):147-55.

15. Reddy K, Sinha P, Kane CMO, Gordon AC, Calfee CS, Mcauley DF. Subphenotypes in critical care: translation into clinical practice. Lancet Respir Med. 2020;8:631-43.

16. Shankar-hari M, Rubenfeld GD. Population enrichment for critical care trials : phenotypes and differential outcomes. Curr Opin Crit Care. 2019;25:489-97.

17. Shaver CM, Bastarache JA. Clinical and biological heterogeneity in acute respiratory distress syndrome. Clin Chest Med. 2014;35(4):639-53.

18. Luo L, Shaver CM, Zhao Z, Koyama T, Calfee CS, Bastarache JA, et al. Clinical predictors of hospital mortality differ between direct and indirect acute respiratory distress syndrome. Chest. 2017;151(4):755-63.

19. Calfee CS, Eisner MD, Ware LB, Thompson BT, Parsons PE, Wheeler AP, et al. Trauma-associated lung injury differs clinically and biologically from acute lung injury due to other clinical disorders*. Crit Care Med. 2007;35(10):2243-50.

20. Reilly JP, Bellamy S, Shashaty MGS, Gallop R, Meyer NJ, Lanken PN, et al. Heterogeneous phenotypes of acute respiratory distress syndrome after major trauma. Ann Am Thorac Soc. 2014;11(5):728-36.

21. Cardinal-Fernández P, Bajwa EK, Dominguez-Calvo A, Menéndez JM, Papazian L, Thompson BT. The presence of diffuse alveolar damage on open lung biopsy is associated with mortality in patients with acute respiratory distress syndrome-a systematic review and meta-analysis. Chest. 2016;149(5):1155-64.

22. Hoelz C, Negri E, Lchtenfels A, Conceicao G, Barbas C, Saldiva P, et al. Morphometric differences in pulmonary lesions in primary and secondary ARDSA preliminary study in autopsies. Pathol Res Pract. 2001;197(8):521-30.

23. Thille AW, Esteban A, Fernández-Segoviano P, Rodriguez J-M, Aramburu J-A, Peñuelas $\mathrm{O}$, et al. Comparison of the berlin definition for acute respiratory distress syndrome with autopsy. Am J Respir Crit Care Med. 2013;187(7): 761-7.

24. Mrozek S, Jabaudon M, Jaber S, Paugam-Burtz C, Lefrant J-Y, Rouby J-J, et al. Elevated plasma levels of sRAGE are associated with nonfocal CT-based lung imaging in patients with ARDS. Chest. 2016;150(5):998-1007.

25. Puybasset L, Cluzel P, Gusman P, Grenier P, Preteux F, Rouby J-J. Regional distribution of gas and tissue in acute respiratory distress syndrome. I. Consequences for lung morphology. Intensive Care Med. 2000;26(7):857-69.

26. Rouby J-J, Puybasset L, Cluzel P, Richecoeur J, Lu Q, Grenier P. Regional distribution of gas and tissue in acute respiratory distress syndrome. II. Physiological correlations and definition of an ARDS Severity Score. Intensive Care Med. 2000;26(8):1046-56.

27. Constantin J-M, Jabaudon M, Lefrant J-Y, Jaber S, Quenot J-P, Langeron $\mathrm{O}$, et al. Personalised mechanical ventilation tailored to lung morphology versus low positive end-expiratory pressure for patients with acute respiratory distress syndrome in France (the LIVE study): a multicentre, single-blind, randomised controlled trial. Lancet Respir Med. 2019;7(10):870-80.

28. Lanza ST, Tan X, Bray BC. Latent Class Analysis With Distal Outcomes: A Flexible Model- Based Approach. Struct Equ Model. 2013;20(1):1-26.

29. Mori M, Krumholz HM, Allore HG. Using latent class analysis to identify hidden clinical phenotypes. JAMA. 2020;324(7):700.
30. Calfee CS, Delucchi K, Parsons PE, Taylor B, Ware LB, Matthay MA. Latent class analysis of ARDS subphenotypes: analysis of data from two randomized Controlled Trials. Lancet Respir Med. 2014;2(8):611-20.

31. Brower RG, Lanken PN, Maclntyre N, Matthay MA, Morris A, Ancukiewicz M, et al. Higher versus lower positive end-expiratory pressures in patients with the acute respiratory distress syndrome. N Engl J Med. 2004;351(4):327-36.

32. Wiedemann HP, Wheeler AP, Bernard GR, Thompson BT, Hayden D, DeBoisblanc $B$, et al. Comparison of two fluid-management strategies in acute lung injury. N Engl J Med. 2006;354(24):2564-75.

33. Famous KR, Delucchi K, Ware LB, Kangelaris KN, Liu KD, Thompson BT, et al. Acute respiratory distress syndrome subphenotypes respond differently to randomized fluid management strategy. Am J Respir Crit Care Med. 2017; 195(3):331-8

34. Delucchi K, Famous KR, Ware LB, Parsons PE, Taylor Thompson B, Calfee CS. Stability of ARDS subphenotypes over time in two randomised controlled trials. Thorax. 2018;73:439-45.

35. Bos LD, Schouten LR, van Vught LA, Wiewel MA, Ong DSY, Cremer O, et al. Identification and validation of distinct biological phenotypes in patients with acute respiratory distress syndrome by cluster analysis. Thorax. 2017;72(10):876-83.

36. McAuley DF, Laffey JG, O'Kane CM, Perkins GD, Mullan B, Trinder TJ, et al. Simvastatin in the acute respiratory distress syndrome. N Engl J Med. 2014 Oct;371(18):1695-703.

37. Calfee CS, Delucchi KL, Sinha P, Matthay MA, Hackett J, Shankar-Hari M, et al. Acute respiratory distress syndrome subphenotypes and differential response to simvastatin: secondary analysis of a randomised controlled trial. Lancet Respir Med. 2018;0(0):1-8.

38. Bernard GR, Uni V, Steingrub J, Matthay MA, Liu KD, Albertson TE, et al. Rosuvastatin for sepsis-associated acute respiratory distress syndrome. N Engl J Med. 2014;23370(5):2191-200.

39. Sinha P, Delucchi KL, Thompson BT, McAuley DF, Matthay MA, Calfee CS. Latent class analysis of ARDS subphenotypes: a secondary analysis of the statins for acutely injured lungs from sepsis (SAILS) study. Intensive Care Med. 2018;44(11):1859-69.

40. Pierrakos $C$, Vincent $J$. The changing pattern of acute respiratory distress syndrome over time: a comparison of two periods. Eur Respir J. 2012;40(3):589-95.

41. Simonis FD, de ludicibus G, Cremer OL, Ong DSY, van der Poll T, Bos LD, et al. Macrolide therapy is associated with reduced mortality in acute respiratory distress syndrome (ARDS) patients. Ann Transl Med. 2018;6(2):2431.

42. Shyamsundar M, McKeown STW, O'Kane CM, Craig TR, Brown V, Thickett DR, et al. Simvastatin decreases lipopolysaccharide-induced pulmonary inflammation in healthy volunteers. Am J Respir Crit Care Med. 2009;179(12) 1107-14.

43. Bonsu KO, Reidpath DD, Kadirvelu A. Effects of statin treatment on inflammation and cardiac function in heart failure: an adjusted indirect comparison meta-analysis of randomized trials. Cardiovasc Ther. 2015;33(6): 338-46.

44. Kitsios GD, Yang L, Manatakis DV, Nouraie M, Evankovich J, Bain W, et al. Host-response subphenotypes offer prognostic enrichment in patients with or at risk for acute respiratory distress syndrome*. Crit Care. 2019;47(12): 1724-34.

45. Kan M, Shumyatcher $M$, Himes BE. Using omics approaches to understand pulmonary diseases. Respir Res. 2017;18(149):1-20.

46. Levitt JE, Rogers AJ. Proteomic study of acute respiratory distress syndrome: current knowledge and implications for drug development. Expert Rev Proteomics. 2016;13(5):457-69.

47. Bos LD, Scicluna BP, Ong DY, Cremer O, van der Poll T, Schultz MJ. Understanding heterogeneity in biological phenotypes of ARDS by leukocyte expression profiles. Am J Respir Crit Care Med. 2019;200(1):42-50.

48. Neudoerffer Kangelaris K, Prakash A, Liu KD, Aouizerat B, Woodruff PG, Erle DJ, et al. Increased expression of neutrophil-related genes in patients with early sepsis-induced ARDS. Am J Phys Lung Cell Mol Phys. 2015;308:1102-13.

49. Sweeney TE, Thomas NJ, Howrylak JA, Wong HR, Rogers AJ, Khatri P. Multicohort analysis of whole-blood gene expression data does not form a robust diagnostic for acute respiratory distress syndrome. Crit Care Med. 2018;46(2):244-51

50. Sinha P, Delucchi KL, Mcauley DF, Kane CMO, Matthay MA, Calfee CS. Development and validation of parsimonious algorithms to classify acute respiratory distress syndrome phenotypes: a secondary analysis of randomised controlled trials. Lancet Respir Med. 2020;8:247-57. 
51. Scicluna BP, van Vught $L A$, Zwinderman AH, Wiewel MA, Davenport EE, Burnham KL, et al. Classification of patients with sepsis according to blood genomic endotype: a prospective cohort study. Lancet Respir Med. 2017; 5(10):816-26.

52. Neyton LPA, Zheng X, Skouras C, Doeschl-Wilson A, Gutmann MU, Uings I, et al. Molecular patterns in acute pancreatitis reflect generalizable endotypes of the host response to systemic injury in humans. Ann Surg. 2020; Available from: https://journals.Iww.com/10.1097/SLA.0000000000003974.

53. Mehta C, Gao P, Bhatt DL, Harrington R. a, Skerjanec S, Ware JH. Optimizing trial design: sequential, adaptive, and enrichment strategies. Circulation. 2009;119(4):597-605.

54. Wenzel SE. Asthma phenotypes: the evolution from clinical to molecular approaches. Nat Med. 2012;18(5):716-25.

55. Corren J, Lemanske RF, Hanania NA, Korenblat PE, Parsey MV, Arron JR, et al. Lebrikizumab treatment in adults with asthma. N Engl J Med. 2011;365(12): 1088-98.

56. Silva IP, Long GV. Systemic therapy in advanced melanoma. Curr Opin Oncol. 2017;29(6):484-92.

57. Chapman PB, Hauschild A, Robert C, Haanen JB, Ascierto P, Larkin J, et al. Improved survival with vemurafenib in melanoma with BRAF V600E mutation. N Engl J Med. 2011;364(26):2507-16.

58. Solomon BJ, Mok T, Kim D-W, Wu Y-L, Nakagawa K, Mekhail T, et al. First-line crizotinib versus chemotherapy in ALK-positive lung cancer. N Engl J Med. 2014;371(23):2167-77.

\section{Publisher's Note}

Springer Nature remains neutral with regard to jurisdictional claims in published maps and institutional affiliations.

Ready to submit your research? Choose BMC and benefit from:

- fast, convenient online submission

- thorough peer review by experienced researchers in your field

- rapid publication on acceptance

- support for research data, including large and complex data types

- gold Open Access which fosters wider collaboration and increased citations

- maximum visibility for your research: over $100 \mathrm{M}$ website views per year

At $\mathrm{BMC}$, research is always in progress.

Learn more biomedcentral.com/submissions 